\title{
Prevalence of unwanted pregnancy in Iranian women: a systematic review and meta-analysis
}

\author{
Rostam Jalali, Masoud Mohammadi ${ }^{*}$, Aliakbar Vaisi-Raygani, Akram Ghobadi and Nader Salari
}

\begin{abstract}
Background: Unwanted pregnancies are considered as one of the most important public health risks. Regarding the importance of the unwanted pregnancy in the country and helping health policy-makers obtain more accurate information on this issue, this study aims to provide a systematic review and meta-analytical on the prevalence of unwanted pregnancies in Iran.

Methods: The present study was carried out using meta-analysis. Articles related to the topic were obtained through SID, Magiran, Scopus, PubMed, and ScienceDirect and Google Scholar databases from 2001 to 2017 , Articles written based on cross-sectional studies were included in the study and other overviews, case-control, cohort, and interventional studies were excluded from the list of articles. Heterogeneity of studies was investigated using $\mathrm{I}^{2}$ index and data analysis was performed in Comprehensive Meta-Analysis software (Version 3).

Results: In 23 articles, the prevalence of unwanted pregnancy in Iranian women was 27.9\% (95\%Cl: 24-32.1\%). The meta-regression analysis was used in two sample sizes and years of study. It was reported that as the sample size and Years increases, the prevalence of the unwanted pregnancy decrease, this difference was also statistically significant $(P=0.000)$.

Conclusion: Considering that the prevalence of unwanted pregnancy is high in Iran, it is necessary that health policy makers take effective measures to enhance the awareness of couples and public information about the risks of the unwanted pregnancy.
\end{abstract}

Keywords: Prevalence, Unwanted pregnancy, Women, Iran, Meta-analysis

\section{Plain English summary}

Unwanted pregnancies are considered as one of the most important public health risks. Given that the overall outbreak in Iran is unclear, the present study raised the question what is the overall Prevalence of Unwanted Pregnancy in Iranian Women throughout the country? The present study was carried out using meta-analysis. Articles related to the topic were obtained through SID, Magiran, Scopus, PubMed, and ScienceDirect and Google Scholar databases from 2001 to 2017, Articles written based on cross-sectional studies were included in the study and other overviews, case-control, cohort, and interventional studies were excluded from the list of

\footnotetext{
* Correspondence: masoud.mohammadi1989@yahoo.com Department of Nursing, School of Nursing and Midwifery, Kermanshah University of Medical Sciences, Kermanshah, Iran
}

articles. In 23 articles, the prevalence of unwanted pregnancy in Iranian women was $27.9 \%$, Considering that the prevalence of unwanted pregnancy is high in Iran, it is necessary that health policy makers take effective measures to enhance the awareness of couples and public information about the risks of the unwanted pregnancy.

\section{Background}

The increasing population growth is one of the most important barriers to economic growth, social progress, and a decrease in the promotion of the health level in modern countries. On the other hand, $50 \%$ of births have been unplanned and $25 \%$ of births have been unwanted pregnancies [1], family planning plays a very important role in controlling population and social balance

(c) The Author(s). 2019 Open Access This article is distributed under the terms of the Creative Commons Attribution 4.0 International License (http://creativecommons.org/licenses/by/4.0/), which permits unrestricted use, distribution, and 
in society, while unwanted and unplanned pregnancies are one of the most important public health risks [2].

Unwanted pregnancy is a pregnancy that is usually accidental and is not requested by one or both parents. According to the conducted studies, 120 million women in developing countries have unwanted pregnancy because of not using family planning methods, this means that one out of five pregnancies is unwanted $[2,3]$. Reports show that in 2008, there were 22 million unsafe abortions due to unwanted pregnancy, resulted in more than 47,000 mothers' mortalities (13\%) [4]. In Iran, despite the availability of contraceptive methods, a significant proportion of pregnancies (more than 25 to 35\%) is still unplanned in different areas due to the use of traditional methods or irregular and incorrect use of preventive methods, and 4000-5000 unwanted pregnancies are occurred annually, out of which $16 \%$ of cases lead to abortion. In spite of government's efforts for family planning, only $55.4 \%$ of family planning equipment have been used, and various studies have reported the incidence of unwanted pregnancy in the range of $18 \%$ to over 35\% [4-6]. Such a situation leads to the reduction of the quality of life, mother's mental disorders, suicide, the occurrence of risky behaviors such as smoking and using alcohol in the mothers [7].

Unwanted pregnancy and its complications is a global issue that affects women, families and the community, and in most cases leads to deliberate abortion or even mother's death. Therefore, the reduction of unwanted pregnancy is followed by reducing maternal mortality in one hand and, reducing hospital burden and costs on the other hand. It can also have a positive effect on improving the level of welfare of couples and the pattern of population growth and economic and social development of society are guaranteed $[8,9]$.

Given that the overall outbreak in Iran is unclear, present study raised the question what is the overall Prevalence of Unwanted Pregnancy in Iranian Women throughout the country?

Therefore, regarding the importance of the unwanted pregnancies in Iran and helping health policymakers obtain more accurate information on this topic, this study aims to provide a systematic and meta-analysis review on the prevalence of the unwanted pregnancies in Iran.

\section{Methods}

This study was a systematic review and meta-analysis and it is the result of the findings extracted from studies on the prevalence of unwanted pregnancy in Iranian women; and the articles included were published either in domestic or foreign journals and the search in Magiran, SID, Medline (PubMed) and ScienceDirect, Scopus and Google scholar databases was limited to articles conducted within March, 2001 to October, 2017.

\section{Search strategy}

The database search process was performed through the use of keywords in Persian, and also through English equivalent of the keywords, i.e., pregnancy, unwanted pregnancy, Iran and their possible combinations. It means that the keywords in Persian were used in search process in Farsi databases and the English equivalents of the keywords were used on English databases; moreover, both keywords in Persian and the English equivalents as mentioned above were used to search in Google scholar search engine and the operators AND, OR were used to search keywords in combination so that to gain full access to all articles. Hence, the operator OR was used to check the common names used for one disorder, e.g., (((((Pregnancy [Title/Abstract]) OR Fertilization [Title/Abstract]) AND unwanted pregnancy [Title/Abstract]) OR Pregnancy Unplanned [Title/Abstract]) AND Women [Title/ Abstract]) OR Female [Title/Abstract]))))) through matching the search term with items on MeSH browser.

\section{Articles selection and evaluation criteria}

First, all articles were collected using the selected keywords and a list of abstracts was prepared after the search was completed. After concealing the profile of the articles, including the name of the journal and name of the author, the full texts of the articles were submitted to the reviewers. Each article was read independently by two reviewers. If the article was rejected, the reason for rejection was mentioned and in cases of disagreement between the two reviewers, the article is evaluated by a third reviewer and the opinion of the third reviewer is taken into account. Articles were in Persian and English and were obtained from cross-sectional studies on the prevalence of unwanted pregnancy in Iranian women and they met the selection criteria to be included in the study, and other review, case-control, cohort, and interventional studies were excluded from the list of articles. In this study, in order to review Gray Literature, i.e., part of the evidence and documentation that was not published or distributed for any reason, a general search on the Google search engine and the review of the related sites were also on the agenda.

\section{Statistical analysis}

In each study, the prevalence of unwanted pregnancy in Iranian women was obtained. $I^{2}$ test was used to examine the heterogeneity of studies. Generally, heterogeneity is classified as three categories: heterogeneity less than 25\% (low level of heterogeneity), between 25 and $75 \%$ (average level of heterogeneity) and more than 75\% (high level of heterogeneity). Data were analyzed using Comprehensive Meta-Analysis software (Biostat, Englewood, NJ, USA version 3 ). The probability of publication bias in results was measured using the funnel plot, the Egger 
test and the significance level of 0.05 . Also, the metaregression test in two factors of the sample size and research year was used to investigate the effects of the potential factors affecting the heterogeneity of the studies.

\section{Results}

\section{Search output}

The study review process was reported based on the PRISMA 2009 process (Fig. 1). A table was prepared that contains information from selected articles including the name of the researcher, the title of the article, the year and place of the study, the number of samples, and the prevalence of unwanted pregnancy in studies (Table 1). Eventually, in the final review, the related articles were entered the meta-analysis stage that as a result 23 appropriate articles were entered to this stage [10-32].

Based on studies on the prevalence of unwanted pregnancy in Iranian women that included articles published either in domestic or foreign journals, and through searching Magiran, SID databases 39 articles, Medline (PubMed) 138 articles and Science Direct 362 articles, Scopus 62 articles and Google Scholar 140 articles were obtained; then articles that met the initial inclusion criteria were included in the study but via primary assessment, the exclusion of 412 duplicate ones left 329 articles that by elimination of another 243 articles unrelated to subject of study and the elimination of 63 articles in a secondary assessment due to the lack of access to the abstract and full text of the articles and because of the poor quality of the articles eventually 23 articles entered the meta-analysis process, the total number of participants in the study was 15 , 076 individuals aged between 10 and 50 years old, the highest sample size was in the study of Serehti et al. [17] in Shahrekord (1925 individuals) and the lowest sample size (102) in the study of Azizi et al. [18] in Kermanshah (Salas Babajani).

\section{Heterogeneity and publication bias}

The heterogeneity of the studies was evaluated using the $\mathrm{I}^{2}$ test which value was $96.5 \%$ showing a high heterogeneity in the studies. Therefore, the random effects model was used to combine the results of the studies. The publication bias was evaluated via funnel plot and Egger's test at a significance level of less than 0.05 , which the publication bias was not statistically significant $(P=0.402)$ (Fig. 2$)$.

\section{Meta-analysis}

Based on the random effects model, it has been shown that the black square is the prevalence rate and the length of the line segment on which the square places is $95 \%$ confidence interval in each study, the rhubarb shows the

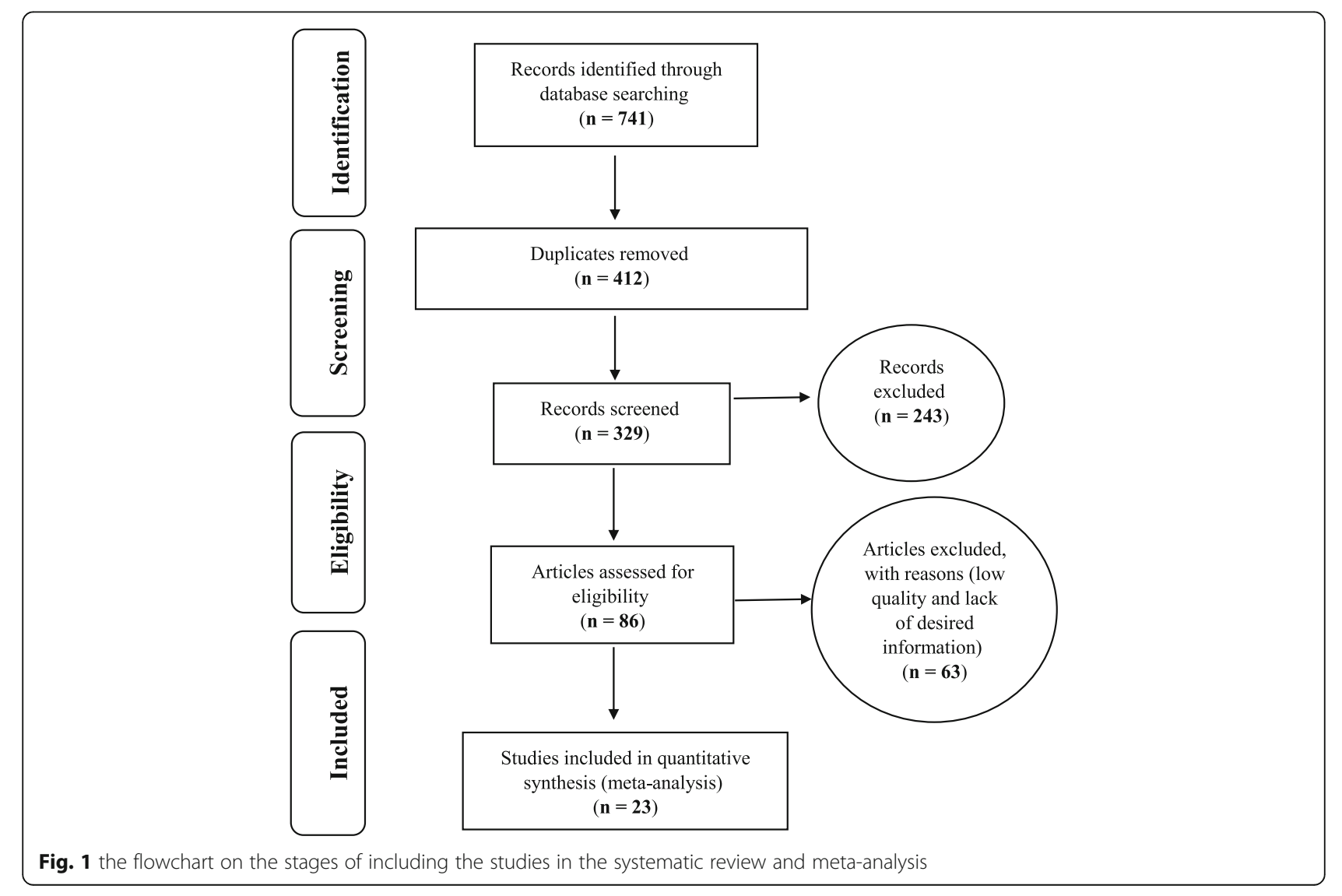


Table 1 Specifications of studies entered the stud

\begin{tabular}{|c|c|c|c|c|c|c|}
\hline Row & Author [References] & Published & Area & Age & Sample size & Prevalence \\
\hline 1 & Kiani [10] & 2013 & Mashhad & $34.9 \pm 5.6$ & 105 & 29.5 \\
\hline 2 & Hassan-Ghasemi [11] & 2013 & Gorgan & $32.1 \pm 7.4$ & 339 & 13 \\
\hline 3 & Abdullahi [12] & 2004 & Mazandaran & $18-35$ & 1200 & 10.6 \\
\hline 4 & Amin shokravi [13] & 2004 & Tehran & $10-49$ & 150 & 31.3 \\
\hline 5 & Zaheri [14] & 2014 & Sanandaj & $20-40$ & 1070 & 25.1 \\
\hline 6 & Ostadnowrozi [15] & 2012 & Kurdistan & $18-36$ & 1134 & 25.1 \\
\hline 7 & Mohammadpourasl [16] & 2005 & Tabriz & $26 \pm 5.4$ & 1576 & 26.7 \\
\hline 8 & Sereshti [17] & 2005 & Shahr e Kord & $25.2 \pm 5.3$ & 1925 & 27.2 \\
\hline 9 & Azizi [18] & 2011 & Kermanshah (Salas e Babajani) & $25.7 \pm 4.1$ & 102 & 40.2 \\
\hline 10 & Jahanfar [19] & 2002 & $\begin{array}{l}\text { Iran (Fars, Sistan and Baluchestan, Hamedan, } \\
\text { Kerman, Mazandaran, Gilan, Khorasan, Khuzestan, } \\
\text { Isfahan and West Azarbaijan) }\end{array}$ & $29.6 \pm 7.1$ & 1548 & 34.9 \\
\hline 11 & Shahbazi [20] & 2006 & Semnan & $20-35$ & 405 & 25.7 \\
\hline 12 & Kahnamoeiaghdam [21] & 2005 & Ardebil & $13-44$ & 600 & 30.8 \\
\hline 13 & Zamani [22] & 2005 & Isfahan (Najafabad) & $24.9 \pm 5.1$ & 788 & 42 \\
\hline 14 & Jarahi [23] & 2014 & Khorasan Razavi (Sarakhs) & $18-35$ & 300 & 21.7 \\
\hline 15 & Namazi [24] & 2014 & Rasht & $27.5 \pm 4.6$ & 270 & 49.3 \\
\hline 16 & Shahbazin [25] & 2015 & Kermanshah (Kangavar) & $31.3 \pm 7.4$ & 248 & 21.2 \\
\hline 17 & Amani [26] & 2010 & Ardebil & $28.2 \pm 6.7$ & 328 & 60.7 \\
\hline 18 & Mirzamoradi [27] & 2017 & Tehran & $15-45$ & 950 & 19.2 \\
\hline 19 & Tavakoli [28] & 2002 & Rafsanjan & - & 356 & 38.8 \\
\hline 20 & Kazemi [29] & 2001 & Zanjan & $20-30$ & 500 & 28 \\
\hline 21 & Mohammadsalehi [30] & 2010 & Arak & - & 352 & 27.8 \\
\hline 22 & Vakili [31] & 2010 & Yazd & $28.3 \pm 5.8$ & 330 & 22.9 \\
\hline 23 & Vizshafar [32] & 2005 & Fars (Grash and Lar) & $26.4 \pm 5.4$ & 500 & 18.1 \\
\hline
\end{tabular}

prevalence rate throughout the country for the whole study. Accordingly, the overall prevalence of unwanted pregnancy in Iranian women is $27.9 \%$ (95\% CI: $24.1-32 \%$ ), the highest prevalence of unwanted pregnancy was in Ardebil with 60.7\% (95\% CI: 3.8-55.65\%) [26] And the lowest prevalence of unwanted pregnancy was in Mazandaran with 10.6\% (95\% CI: 9.5-12\%) [12] (Fig. 3).

\section{Sub-group analysis}

Table 2 reports the results of the different sub-group analysis according to the Years of publication, and Sample size (Table 2).

\section{Meta-regression}

In order to investigate the effects of potentially effective factors on heterogeneity in the prevalence of unwanted pregnancy in Iranian women, meta-regression was used for two factors of sample size and the year of study (Figs. 4 and 5). The prevalence of the unwanted pregnancy also decreases with increasing sample size in the studies, and this difference was statistically significant
$(P=0.000)$ (Fig. 4). It was also reported in (Fig. 5) that, as the year of the study progresses, the frequency and prevalence of unwanted pregnancy decrease. This difference was also statistically significant $(P=0.000)$.

\section{Discussion}

Unwanted pregnancy, in addition to imposing economic costs on the whole community, affects the health of the mother and her survival. During pregnancy, the mother may suffer from pregnancy complications, especially anemia, and may be at risk of various diseases that affect her physical and mental health [30-32]. According to the World Health Organization (WHO), over one-third of the pregnancies were reported unwantedly and most unwanted pregnancies are related to the developing countries [33], 60\% were reported in the US study [34], while in another study in the United States, $17 \%$ of unwanted pregnancies have been over 35 years old [35]. In addition, in the U.S national survey [36] and in the Lawrence [37] and Ventura's [38] studies in 2011 and 2012 in the United States, the prevalence of unwanted 


\section{Funnel Plot of Standard Error by Logit event rate}

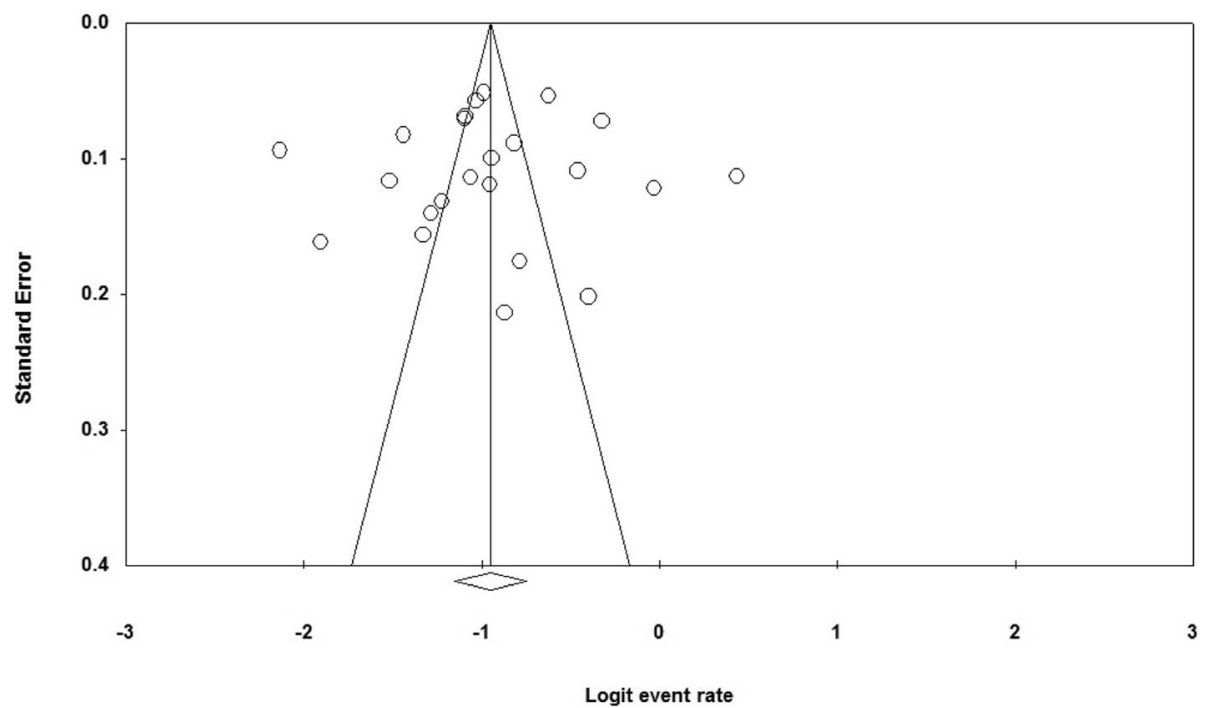

Fig. 2 Funnel Plot. Results of unwanted pregnancy prevalence in Iranian women

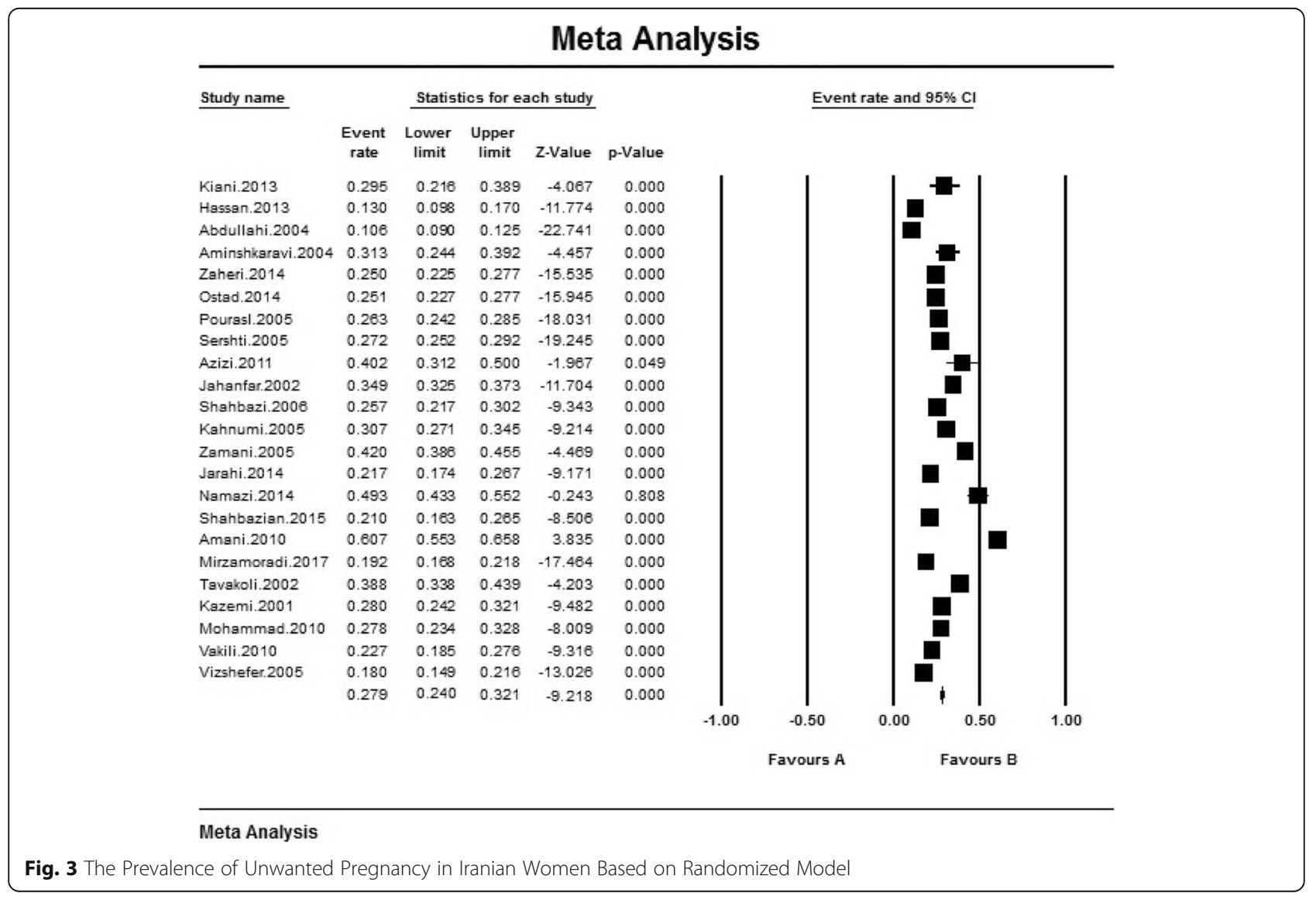


Table $\mathbf{2}$ The results of sub-group analyses

\begin{tabular}{lllllll}
\hline Variables & & No. studies & Prevalence\% (95\% Cl) & $I^{2}(\%)$ & $P$ value & No. participants \\
\hline Years & $2001-2006$ & 11 & $27.5(22.5-33.1)$ & 96.8 & 0.000 & 9548 \\
& $2007-2012$ & 5 & $34.3(21.9-49.3)$ & 97.3 & 0.000 & 2246 \\
& $2013-2017$ & 7 & $24.3(17.8-32.3)$ & 95.1 & 0.000 & 3282 \\
Sample size & $\leq 500$ & 14 & $29.3(23-36.7)$ & 95.6 & 0.000 & 4285 \\
& $500-1000$ & 3 & $29.8(18-45)$ & 98 & 0.000 & 2338 \\
& 1000 & 6 & $24(18.7-30.3)$ & 97.4 & 0.000 & 8453 \\
\hline
\end{tabular}

pregnancy has been reported to be $49 \%$, in Kenya this prevalence is $24 \%$ [39], in Ethiopia 36.5\% [40], The unwanted pregnancy prevalence in Nepal [41], the unwanted pregnancy rate of $68 \%$ of cases per 1000 women was in the fertility age.

Of factors affecting unwanted pregnancy are the age of the husband with an age difference of 4 or more years, the marriage age, the age of the first intercourse, the lack of knowledge and the use of contraceptive methods, the low economic and social situation. In the results of this study, the unwanted pregnancies were at older ages and studies have shown that husband's age has a significant relationship with the prevalence of unwanted pregnancy and this relationship is inverse indicating the fact that increasing husband's age and unwanted pregnancy by the husband and on the other hand his failure to cooperate with his wife to carry out safe prevention services lead to an increase in unplanned pregnancies $[26,27]$. The unwanted pregnancy, in addition to maternal health and the risk of abortion, afflicts the mother's mental health and leads to mental illness and even suicide [26]. Various studies have reported that $60 \%$ of suicides in pregnant women have been in the third trimester and after knowing about the unwanted pregnancy [26-29]. The unwanted pregnancy is one of the important indicators of quality assessment of family planning services, which can endanger the pregnancy health as it was mentioned. The unwanted pregnancy across the world is a threat for mother and child health due to the lack of family support and it is among the causes that increase mothers' mortality and a major obstacle to the improvement of reproductive and sexual health [13]. Compared to other children, children born in unwanted pregnancies are premature with low birth weight and they use breastfeeding less [42]. Unwanted children are more likely to be bothered or neglected by parents and will have a more limited emotional connection with the mother. Also, such conditions make these children have low self-confidence [23]. Unwanted pregnancy is also one of the causes of a large increase in the size of the population, which makes housing, educational space, food shortages, annual income decline, inflation, poor quality of health care, the increasing overhead, the increasing unemployment rate. Therefore, in order to achieve the goals of social, economic and cultural development, it

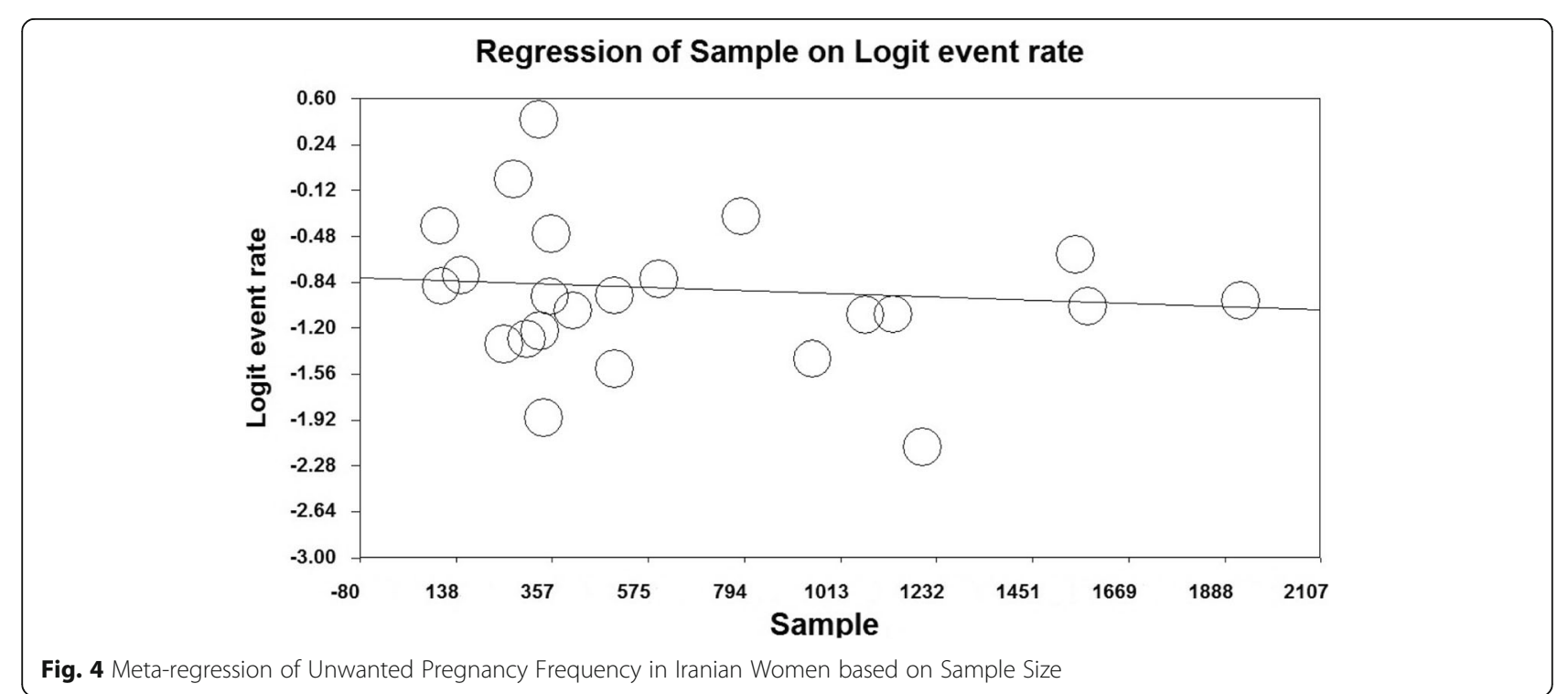




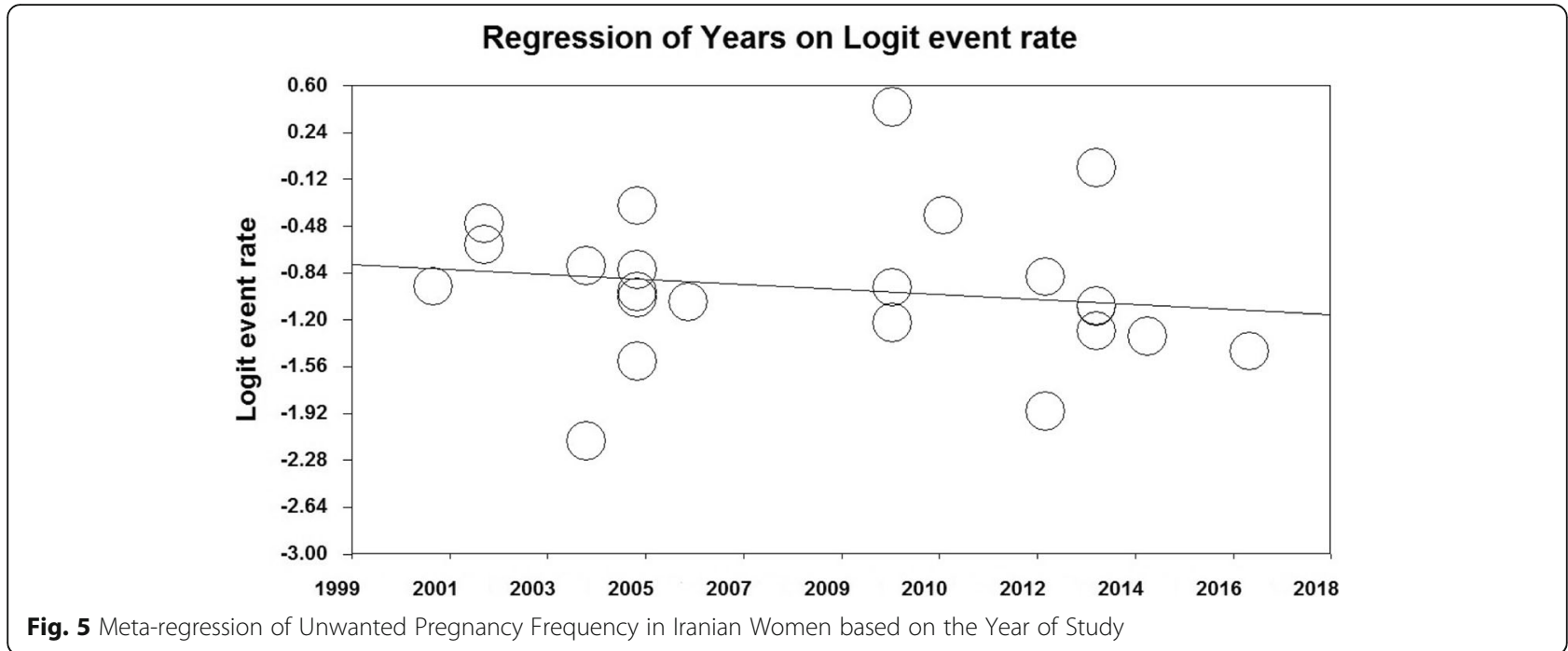

is necessary to improve modernization programs, social justice, a proper coordination between population and the development programs [43].

According to reports, 75 million out of 175 million registered pregnancies were unwanted worldwide, and according to the World Health Organization reports, such conditions make it possible to witness about 20 million dangerous abortions, resulting in deaths of 60-100 thousand mothers per year. In Iran, about 80, 000 intentional abortions have been reported annually due to the unwanted pregnancy, many of which result in maternal death or inability due to unsafe abortions. Considering that the prevalence of unwanted pregnancy is high and the unwanted pregnancies are mainly due to family planning inappropriate behaviors, one third-one fourth of mothers' mortalities can be prevented by the correction of family planning behaviors and the increase of awareness of couples regarding the risks of unwanted pregnancies [43-45]. Many unwanted pregnancies are reduced and prevented by enhancing men's awareness, especially at older ages, and with the improvement of these conditions, it is possible to reduce the number of abortions due to the unwanted pregnancies and increase the welfare of the community.

\section{Strengths and limitations}

One of the strengths of the present study was the provision of an overall Prevalence of Unwanted Pregnancy in Iranian Women for the first time. Moreover, meta-regression was used in this study for the two factors of sample size and publication year. On the other hand, the most important limitations of the study were related to the inaccessibility of the full-text of some retrieved studies and the lack of information required in some studies.

\section{Conclusion}

Considering that in Iran the prevalence of unwanted pregnancy is high, health policy makers need to take effective measures to increase awareness among couples and publicly inform about the risks of the unwanted pregnancy.

\section{Abbreviations}

PRISMA: Preferred Reporting Items for Systematic Reviews and Meta-Analysis; SID: Scientific Information Database; STROBE: Strengthening the Reporting of Observational Studies in Epidemiology for cross- sectional Study;

WHO: World Health Organization

\section{Acknowledgements}

The authors thank the faculty members of the Faculty of Nursing and Midwifery, Kermanshah University of Medical Sciences.

\section{Authors'contributions}

MM and RJ contributed to the design, statistical analysis, participated in most of the study steps. MM and AVR prepared the manuscript. MM and RJ and $\mathrm{AGH}$ and NS assisted in designing the study, and helped in the,

interpretation of the study. All authors have read and approved the content of the manuscript.

\section{Funding}

Not declared.

Availability of data and materials

Datasets are available through the corresponding author upon reasonable request.

\section{Ethics approval and consent to participate}

Ethics approval was received from the ethics committee of deputy of research and technology, Kermanshah University of Medical Sciences. Reference Number: IR.KUMS.REC.1398.420.

Consent for publication

Not applicable.

Competing interests

The authors declare that they have no competing interests. 
Received: 16 December 2018 Accepted: 2 September 2019 Published online: 04 September 2019

\section{References}

1. Goshtasebi A, Vahdaninia M. Patterns of contraceptive use in urban areas of Kohgiluyeh-Boyerahmad in 2004. Med J Reprod Infertil. 2006;7(3):252-9.

2. Mahoori $\mathrm{KH}$, Amirian M. Unwanted pregnancies and its related factors in pregnant women referredto health centers in Bandar Abbas. Med J Hormozgan Univ. 2009;13(1):25-32.

3. Ghazizadeh S, Lessan-Pezeshki M, Khatami M, Mahdavi M, Razeghi E, Seifi S, et al. Unwanted pregnancy among kidney transplant recipients in Iran. Transplant Proc. 2005;37:3085-6.

4. Sadat-Hashemi SM, Ghorbani R, Majdabadi HA. And Farahani FK. Factors associated with contraceptive use in Tehran,Iran. Eur J Contracept Reprod Health Care 2007; 12:148-153.

5. Nojoumi M, Zeinali Z. Study of unwanted pregnancy prevalence and related factors inWomen referred to prenatal clinics of Akbar Abadi and Rasoul-eAkram hospitals in 2002. Jran Uni Med Sci. 2005;12:195-200.

6. Malek $\mathrm{AH}$. Evaluation of family planning programs in the Tehran of Iran. J Family Health. 1996;1 (1):3-18

7. Forouzandeh N, Delaram M, Deris F. The quality of mental health status in pregnancy and it's contributing factors on women visiting the health care centers of Shahrekord. Med J Reprod Infertil. 2003;2:146-55.

8. Peyman N, Hidarnia AR, Ghofrani PF, et al. The relationship between perceived self-efficacy and contraceptive behaviors among Iranian women referring to health centers in Mashhad in order to decrease unwanted pregnancies. Reprod Infertil. 2007;8:78-90.

9. Ross JA, Maudin WP. Effort and achievement in National Family Planning Programs. World Health Forum. 1994;15(3):46-9.

10. Kiani MA, Khakshour A, Vakili R, Saeedi M, Mosavi Gagarmi SM. Prevalence of unwanted pregnancy and its related factors in women Mashhad City in 2013. J North Khorasan Univ Med Sci. 2013;5(2):421-9.

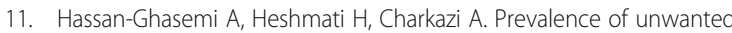
pregnancy and its related factors in interruption method users in Gorgan health-care centers in 2010. J Health Syst Res. 2013:9(11):1201-13.

12. Abdullahi F. Mohammadpour tahmtan RA. Investigating the consequence of unwanted pregnancy in women referring to maternity Hospital of Mazandaran Medical Sciences Hospital 1999-2000. Mazandaran J Med Sci. 2004;14(44):87-93.

13. Amin shokravi F, Chapman PHH. Study of Factors Affecting Unwanted Pregnancy in a Group of Pregnant Women in Tehran. Fertil Infertil Q. 2004;2: 249-58.

14. Zaheri F, Ranaei F, Hasheminasab L, Karime R, Shahoi R. Unwanted pregnancy and its related factors in pregnant women referring to health centers in Sanandaj 2011. IJOGI. 2014;17(132):10-5.

15. Ostadnowrozi N, Zokaei M, Khorramdel ZH, Zandvakili F. The prevalence of unwanted pregnancy and related factors in pregnant women in Kurdistan Province 2012. J Neyshabur Univ Med Sci. 2014;2(2):44-9.

16. Mohammadpourasl A, Rostami F, Ayvanbagha R, Torabi SH. The prevalence of unwanted pregnancy and multivariate analysis of related factors in Tabriz City. J Islamic Azad Univ Med Sci. 2005;15(4):201-6.

17. Sereshti M, Delaram M, Rafieian M. Prevalence and causes of unwanted pregnancy in terms of pregnant women. J Hamadan Nurs Midwifery Fac. 2005;13(24):8-14.

18. Azizi A, Amirian F, Pashaie T, Amirian M. Prevalence of unwanted pregnancy and its relationship with quality of life related with health in pregnant women in Salas city (Kermanshah province),1385. J Obstet Gynecol Infertil. 2011:14(5):24-9.

19. Jahanfar Sh, RamezaniTehrani F, Sadat Hashemi M. Assessment of unwanted pregnancies incidence in women who refering to hospital health center of 10 city of Iran. TUMJ. 2002;60)4(:334-340.

20. Shahbazi A, Ghorban R, Akbarifar M. Prevalence of unwanted pregnancy and its related factors in pregnant women referring to Semnan labs. Komesh. 2006;7(3,4):133-7.

21. Kahnamoeiaghdam F, Mohammadi MA, Dadkhah B, Asadzadeh F, Afshinmehr M. Prevalence and some factors associated with unwanted pregnancy in pregnant women referring to job centers in Ardebil 2001. J Ardabil Univ Med Sci. 2005;5(2):167-71.

22. Zamani F, Bashar Doost N, Rajabi Z. Unwanted pregnancy in rural women of Najafabad. Feyz. 2005;33(9):61-56.
23. Jarahi $L$, Zavar A, Nematshahi M. Frequency of unwanted pregnancy events and related factors in pregnant women in Sarakhs. IJOGI. 2014:17(124):8-14

24. Namazi A. The investigation of demographic variables associated with the phenomenon of unwanted pregnancy in Rasht. Uarterly nursing of vulnerable groups. NJV. 2014;1(2):29-38.

25. Shahbazin S, Gholamy A. Prevalence of unintended pregnancy and its related factors in Kermanshah, Kangavar city (West Iran). J Commun Health Res. 2015:4(1):19-28.

26. Amani F, Bashiri J, Nahanmoghadam N, Tabaraei Y. Application of logistic regression model in investigating factors affecting unwanted pregnancy. J Qom Univ Med Sci. 2010;14(1):32-6.

27. Mirzamoradi M, Saleh M, Jamali M, Bakhtiyari M, Pooransari P, Gargari SS Factors related to unwanted pregnancies and abortion in the Northern District of the City of Tehran. Iran Women Health. 2017. https://doi.org/10. 1080/03630242.2017.1342738.

28. Tavakoli M, Rafiee G, Bakhshi H, Moosavi S, Shafiee N. Unwanted Pregnacy and related factors in 1995 in Rafsanjan. JRUMS. 2002;1(1):20-5.

29. Kazemi AN, Kosha A, Tadayon P, Mosavinasab N. The rate and causes of unwanted pregnancy in 500 pregnant women referring to Zanjan hospitals 1999. J Zanjan Univ Med Sci. 2001;37:39-45.

30. Mohammadsalehi N, Mohammadbaigi A. Prevalence of unplanned pregnancies and related factors in Arak 2007. J Sci Health. 2010;5:122-3.

31. Vakili M, Shahbazi $H$, Dehghani MH. The Prevalence of Unintended Pregnancies and its Related Demographic Factorsin Hospitals of Yazd City 2008. tbj. 2011;9(4):23-35.

32. Vizshafar F, Mehdizadeh Naderi KH. Prevalence of unwanted pregnancy and its relevant factors in patients referred to Lar and Grash hospital. Iran jl Obstet Gynecol Infertil. 2005;8:101-10.

33. World Health Organization. Make every mother and child count. The world health report. 1st Edition. Geneva,Switzerland: WHO Press; 2005.

34. Chavkin W. Unwanted pregnancy in Armenia--the larger context. Am J Public Health. 1998;88(5):732-3.

35. Reinprayoon D. Intrauterine contraception. Curr Opin Obstet Gynecol. 1992 Aug; $4(4): 527-30$

36. Kost K, Forrest JD. Intention status of U.S. births in 1988: Differences by mothers' socioeconomic and demographic characteristics. Fam Plann Perspect. 1995:27(1):11-7.

37. Lawrence BF, Mia RZ. Unintended pregnancy in the United States: incidence and disparities. J Orig Res Article Contracept. 2011;84(5):478-85.

38. Ventura SJ, Curtin SC, Abma JC, Henshow SK. Estimated pregnancy rates and rate pregnancy outcome for the United States, 1990-2008. Natl Vital Stat Rep. 2012;60(7):1-22

39. Ikamari L, Izugbara C, Ochako R. Prevalence and determinants of unintendent pregnancy among women in Neirobi Kenya. J Pregnancy Childbirth. 2013;69(13). https://doi.org/10.1186/1471-2393-13-69.

40. Teshom F, Hailu AG, Teklehaymanot AN. Prevalence of unintended pregnancy and associated factors among married pregnant women in Ganji woreda west Wollega Oromia region, Ethiopia. J Sci Public Health. 2014;2(2): 92-101.

41. Puri M, Singh S, Sundaram A, Hussain R, Tamang A, Crowell M. Abortion incidence and unintended pregnancy in Nepal. Int Perspect Sex Reprod Health. 2016 Dec 1;42(4):197-209.

42. Hickey MT, Shedlin MG. Emergency contraceptive pill users' risk perceptions for sexually transmitted infections and future unintended pregnancy. J Am Assoc Nurse Pract. 2017:29(9):527-534.

43. Sedgh J, Bankole A, Oye-Adeniran B, Adewole IF, Singh S, Hussain R. Unwanted pregnancy and associated factors among Nigerian women. J Intern Fam Plan Perspect. 2006;32(4):175-84.

44. Jarahi L, Meysamie A. P, Fayaz Bakhsh A. Assessment of Attitude and Knowledge about Intentional Abortion in Pre-married Females. Qom Univ Med Sci J, 2012; 6(1):54-59.

45. Callahan R, Becker S. Unmet need, intention to use contraceptives and unwanted pregnancy in rural Bangladesh. Int Perspect Sex Reprod Health. 2014:40(1):4-10.

\section{Publisher's Note}

Springer Nature remains neutral with regard to jurisdictional claims in published maps and institutional affiliations. 